\title{
Experiences with using persuasive technology in a diet trial for older adults
}

\author{
L.M. van der Lubbe \\ l.m.vander.lubbe@vu.nl \\ Computer Science, Vrije Universiteit \\ Amsterdam \\ Amsterdam, the Netherlands
}

\author{
M.C.A Klein \\ michel.klein@vu.nl \\ Computer Science, Vrije Universiteit \\ Amsterdam \\ Amsterdam, the Netherlands
}

\author{
M. Visser \\ Department of Health Sciences, \\ Faculty of Science, and the \\ Amsterdam Public Health research \\ institute, Vrije Universiteit \\ Amsterdam \\ Amsterdam, the Netherlands
}

\author{
H.A.H Wijnhoven \\ Department of Health Sciences, \\ Faculty of Science, and the \\ Amsterdam Public Health research \\ institute, Vrije Universiteit \\ Amsterdam \\ Amsterdam, the Netherlands
}

\begin{abstract}
The PROMISS trial studies the effect of dietary advice to increasing protein intake on physical function in older adults with a relatively low protein intake, to promote healthy ageing. Part of this 6-months trial is the persuasive technology sub study, in which a tablet application using persuasive communication techniques and a specifically designed foodbox, both used for diet tracking, are provided to 48 participants. In this paper we present the results of our sub study for technology adherence, protein intake, experience of dietary advice and technology, and the effect of gamification on protein knowledge. Our results show that participants positively evaluate the tablet, but negatively evaluate the foodbox. The adherence of tablet users within the trial is high (on average $83 \%$ or 133 days), but there are no significant differences in the change of protein intake for our participants, compared to the 41 other participants in the intervention conditions of the trial. Based on these results we conclude that a diet tracking application designed for older adults is a feasible and appreciated tool to use within a dietary intervention study in older persons.
\end{abstract}

\section{CCS CONCEPTS}

-Applied Computing $\rightarrow$ Health Informatics; $\bullet$ Human-centered computing $\rightarrow$ User studies; Usability testing; Tablet computers; • Software and its engineering $\rightarrow$ Software development techniques.

Permission to make digital or hard copies of all or part of this work for personal or classroom use is granted without fee provided that copies are not made or distributed for profit or commercial advantage and that copies bear this notice and the full citation on the first page. Copyrights for components of this work owned by others than ACM must be honored. Abstracting with credit is permitted. To copy otherwise, or republish, to post on servers or to redistribute to lists, requires prior specific permission and/or a fee. Request permissions from permissions@acm.org.

PETRA 2021, June 29-July 2, 2021, Corfu, Greece

(c) 2021 Association for Computing Machinery.

ACM ISBN 978-1-4503-8792-7/21/06 . \$ \$15.00

https://doi.org/10.1145/3453892.3458686

\author{
I. Reinders \\ Department of Health Sciences, \\ Faculty of Science, and the \\ Amsterdam Public Health research \\ institute, Vrije Universiteit \\ Amsterdam \\ Amsterdam, the Netherlands
}

\section{KEYWORDS}

persuasive technology, gamification, older adults, evaluation study, diet complience, user experience

\section{ACM Reference Format:}

L.M. van der Lubbe, M.C.A Klein, M. Visser, H.A.H Wijnhoven, and I. Reinders. 2021. Experiences with using persuasive technology in a diet trial for older adults. In The 14th PErvasive Technologies Related to Assistive Environments Conference (PETRA 2021), June 29-July 2, 2021, Corfu, Greece. ACM, New York, NY, USA, 8 pages. https://doi.org/10.1145/3453892.3458686

\section{INTRODUCTION}

As populations are ageing, healthy ageing becomes more important. Healthy nutrition can contribute to this. Research has shown that smartphone applications (apps) used during dietary interventions have a higher adherence compared to websites or paper diaries [1]. Moreover, it is shown that apps can improve the diet compliance of participants, e.g. [3]. Creating a specific app that meets the needs of the target group, is preferred over using a general journal [2].

Gamification is used in many different domains, among which is healthy lifestyle [4]. Gamification can be described as "the intentional use of game elements for a gameful experience of non-game tasks and contexts" [7]. One of the main goals of adding gamification to an app is to stimulate the motivation of users, to increase the outcomes of the app. Although the ease of use of gamification declines over age [5], it is used for older adults in different contexts; e.g. different rehabilitation or prevention games, for example to make physical training to prevent falling more fun, e.g. [8].

In order to investigate how persuasive technology can be used to increase protein intake in elderly, we have developed a tablet application and a so-called foodbox [9, 10]. This is studied in an experiment, in which participants used the system during the 6months PROMISS trial. The aim of this trial is to increase the protein intake in older adults with a relatively low protein intake [6]. In this 6-months trial, the effect of protein on physical function is studied.

The current paper describes the main outcomes of the persuasive technology sub study of the PROMISS trial. These main outcomes 
aim to answer the main research questions, and are a selection of all analyses performed on the gathered data. First, in Section 2, the method is explained. In Section 3, an overview of the participants is given, followed by the analyses of different research questions. Finally, the conclusion and discussion (Section 4) summarise the results and discusses possible limitations and future possibilities.

\section{METHOD}

The app is provided to our participants on a dedicated tablet. The app is a diet journal, in which participants can register their intake in two ways: directly entering the protein value of the meal, or by choosing products to create a meal. In the latter case, the app calculates the protein value of the meal. The app can also help to replace products in a meal, keeping the protein value the same. Registering intake can be done for each eating moment in the participant's personal dietary advice. The app gives an overview of the protein value of each meal and the whole day, and compares it to the thresholds in the personal dietary advice. Moreover, the application uses persuasive communication in the notification messages that remind participants of their eating moments. Next to the app, the foodbox is a custom made box in which specific protein products provided in the trial can be stored. Taking them out of the box triggers a notification in the app. More details on the design of the system can be found in [9]. In a second variant of the app, gamification elements (rewards, achievements, a profile, and mini-games) are added. These elements are added to study their added value for the adherence, but also for increasing protein knowledge (by the mini-games) and making the app more fun to use. More details on the design of the gamified variant can be found in [10].

The persuasive technology sub study is only performed in the PROMISS trial site in the Netherlands. This trial consists of three study groups: a control group and two intervention groups, in which participants receive a personalised dietary advice. Participants in the intervention groups could opt-in to the sub study, as they need to get a dietary advice that can be put in the app. Only one participant per household can be included, because it is likely that participants living together influence their outcomes by working together. The sub study shares the measure moments with the trial, namely baseline, 3-month and 6-month. Participants are free to stop using the technology provided in the sub study earlier, the measure moments remain the same.

The PROMISS trial aims on increasing the protein intake of older adults with a relatively low protein intake. The aim of the dietary advice is to increase participants' protein intake to $1.2 \mathrm{~g} / \mathrm{kg}$ adjusted $\mathrm{BW} / \mathrm{d}$ (this measure is explained in Table 1). Products are valued according to a protein point system designed for this trial. More details on the design of the trial can be found in its design paper [6]. The app is designed using the same information on products and protein as all participants of the PROMISS trial receive in an information booklet.

The sub study has two conditions: the normal and the gamification condition. The assignment to these conditions is semirandomly, because the inclusion for the gamification condition starts later due to logistical reasons, and we aim to keep the size of the groups equal. Next to this, the foodbox is a storage box for protein products provided to some participants in the trial, that can automatically register the consumption of these products. As not all participants receive the products that can be registered by the foodbox, and as the number of foodboxes available is limited, not all participants will receive one, regardless of their study condition.

The sub study aims to answer the following main research questions (RQ):

(1) How adherent are participants to using the persuasive technology?

(2) Does using persuasive technology increase protein intake?

(3) Does persuasive technology improve the experience of the diet?

(4) How do participants experience the persuasive technology?

(5) Does the gamification improve the participants' knowledge on protein points?

Table 1: Overview of different data sources

\begin{tabular}{|c|c|c|c|c|}
\hline Data type & Explanation & Measured & $\begin{array}{l}\text { Participant } \\
\text { group }\end{array}$ & RQ \\
\hline Tablet data & $\begin{array}{l}\text { Logging of partic- } \\
\text { ipant interaction } \\
\text { with app (e.g. which } \\
\text { buttons clicked, } \\
\begin{array}{l}\text { which products } \\
\text { chosen). }\end{array}\end{array}$ & $\begin{array}{l}\text { During } \\
\text { tablet use }\end{array}$ & Sub study & $\begin{array}{l}1, \\
2, \\
4, \\
5\end{array}$ \\
\hline $\begin{array}{l}\text { Mean pro- } \\
\text { tein intake } \\
\text { in } \mathrm{g} / \mathrm{kg} \\
\text { adjusted } \\
\mathrm{BW} / \mathrm{d}\end{array}$ & $\begin{array}{l}\text { Mean protein intake } \\
\text { in gram per kilo- } \\
\text { gram body weight } \\
\text { per day, adjusted } \\
\text { for the BMI of the } \\
\text { participant. For } \\
\text { participants with a } \\
\text { low/high BMI, their } \\
\text { protein intake is } \\
\text { calculated based on } \\
\text { a healthy BMI. }\end{array}$ & $\begin{array}{l}\text { At baseline, } \\
\text { 3-months, } \\
\text { and } \\
\text { 6-months }\end{array}$ & All & 2 \\
\hline $\begin{array}{l}\text { Dietary ad- } \\
\text { vice evalua- } \\
\text { tion }\end{array}$ & $\begin{array}{l}\text { General evaluation } \\
\text { questions about how } \\
\text { participants experi- } \\
\text { enced/value the di- } \\
\text { etary advice. }\end{array}$ & $\begin{array}{l}\text { At } \\
\text { 6-months }\end{array}$ & All & $\begin{array}{l}3, \\
5\end{array}$ \\
\hline $\begin{array}{l}\text { Persuasive } \\
\text { technology } \\
\text { evaluation }\end{array}$ & $\begin{array}{l}\text { Questionnaire } \\
\text { about user experi- } \\
\text { ence and expected } \\
\text { effectiveness of } \\
\text { the persuasive } \\
\text { technology. }\end{array}$ & $\begin{array}{l}\text { At } \\
\text { 6-months }\end{array}$ & Sub study & 4 \\
\hline
\end{tabular}

To answer these questions, different data sources can be used, which is explained in Table 1 . The measures for the dietary advice can be found in Appendix A.1. The persuasive technology questionnaire evaluates the experienced effectiveness and user-friendliness of the tablet and the foodbox, the notifications showed in the app and the gamification elements, using 7-point Likert scales. All questions of this questionnaire can be found in Appendix A.2. The questionnaires are custom made for this study. We try to get more details on specific aspects of the system, and therefore decide to custom make our questionnaires. Moreover, we ensure that older adults understand the wordings by making the statements concrete about specific aspects. In cases where statistical tests are used to 
Trial participants

Sub study participants

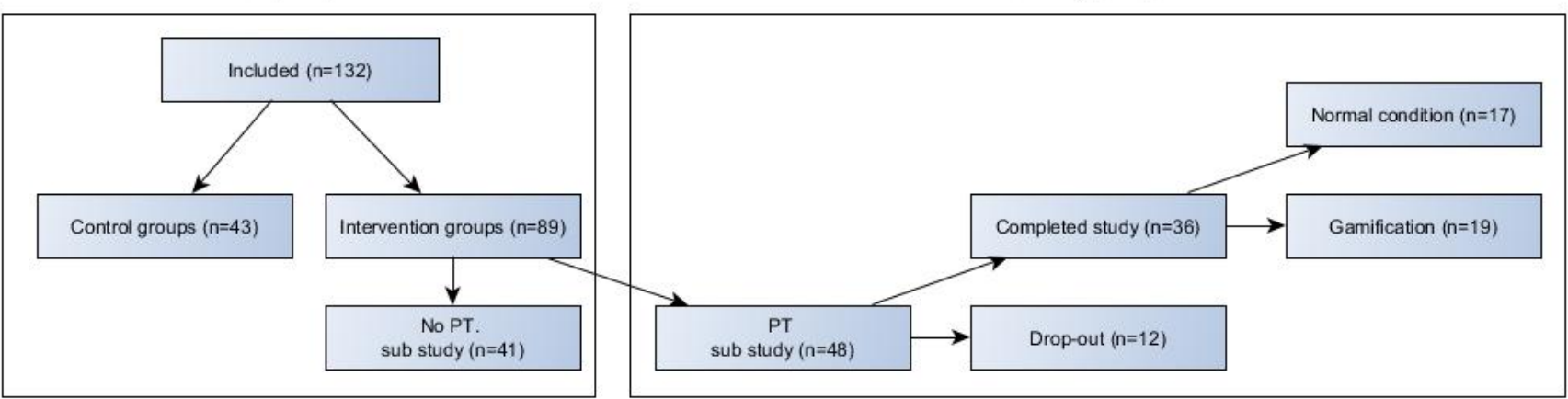

Figure 1: Overview of participants in trial and sub study

answer a research question, we use a threshold of 0.05 for significance. In tables in Section 3, we indicate significant results with an asterisk $\left({ }^{*}\right)$.

Due to the COVID-19 pandemic in $2020^{1}$, it was not possible to conduct the final measurements of the participants for some time. Due to this, $14 \%$ of the participants were able to use the tablet for an extended period. We use 200 days (normal maximum duration) of usage as a cut-off point. Above that, we mark it as 'COVID-19 extension'. Whether the full extended trial, or the trial period (of maximum 200 days) is used, is indicated in the analyses.

\section{RESULTS}

\section{Participants}

An overview of the participants in the trial in the Netherlands, and the persuasive technology sub study (PT) can be found in Figure 1. In total, 48 participants take part in our sub study. Participants that do not fill in the persuasive technology evaluation questionnaire or that have $\leq 20$ days of input on the tablet are excluded from analysis and considered drop-out. In total, 12 participants dropped out, of which 3 also dropped out of the trial. For this data analysis we focus on the 36 PT participants and the 41 participants that are not in the PT group (no PT). Five participants from the PT group have data input on the tablet for more then 200 days, we consider those five the COVID-19 extension group. The PT group contains 15 females and 21 males, with a mean age of 74 (SD = 4.739). The majority of the participants have an education level of secondary education or higher. There are 17 participants in the normal condition, and 19 participants in the gamification condition. In total 26 participants received a foodbox. Participants could stop using the foodbox whenever they wanted, without becoming a drop-out.

\subsection{Adherence}

Figure 2a shows the duration of the trial for the PT group, specifying the number of days in which they did, and in which they did not have input. On average, participants used their tablet for 133 days $(\mathrm{SD}=51.033)$. To measure the length of a tablet usage period, we

\footnotetext{
${ }^{1}$ https://time.com/5791661/who-coronavirus-pandemic-declaration/
}

used the first and last date on which a participant registered any input. Figure $2 \mathrm{~b}$ shows the duration of the trials of five participants with a trial period of $>200$ days. They used their tablet on average for 196 days $(S D=57.191)$. Figure 2c shows the division of days with and without input, for this figure the full duration of the participants in the extended trial period is used, as this is a relative graph. On average, participants used the tablet $83 \%(\mathrm{SD}=16.603 \%)$ of the total tablet use days. Based on the average number of input days and the relative adherence, we consider the adherence of participants high.

When including the 12 drop-out participants in the analysis of the adherence, the overall adherence lowers to 104 days $(\mathrm{SD}=$ $68.485)$ and $76 \%(\mathrm{SD}=28.724)$. There are four participants that did not have any interaction with the system. When excluding those, the average adherence is 114 days $(\mathrm{SD}=63.439)$ and $83 \%(\mathrm{SD}=$ 17.866). Although the average adherence lowers, it is still more than half of the trial period ( 6 months) and the ratio of active days is the same as the adherence ratio of the PT participants.

\subsection{Persuasive technology and protein intake}

Table 2 shows the p-values from Student's t-tests comparing the protein intake of the PT group, with the no PT group. None of the means is significantly different: using the tablet does not change the protein intake of participants.

Figure 3a shows the percentage of participants in the PT and no PT groups that reached the goal of 1.2 protein intake in $\mathrm{g} / \mathrm{kg}$ adjusted BW/d for the 3-month measure moment. The difference between how many participants reached the goal in each group is not significant ( $p$-value $=0.490$ ). Figure $3 \mathrm{~b}$ shows this for the 6-months measurement. Again, the differences between the two groups are not significant ( $\mathrm{p}$-value $=0.621$ ). In both groups, the number of participants that stick with the goal protein intake decreases at 6-months compared to the 3-months measure. However, the change in the group of tablet users is smaller compared to the other participants of the intervention groups.

To test whether the number of days that a PT participant uses the app influences the protein intake, we calculated the Pearson correlation and its $\mathrm{p}$-value for the final protein intake. Both for 


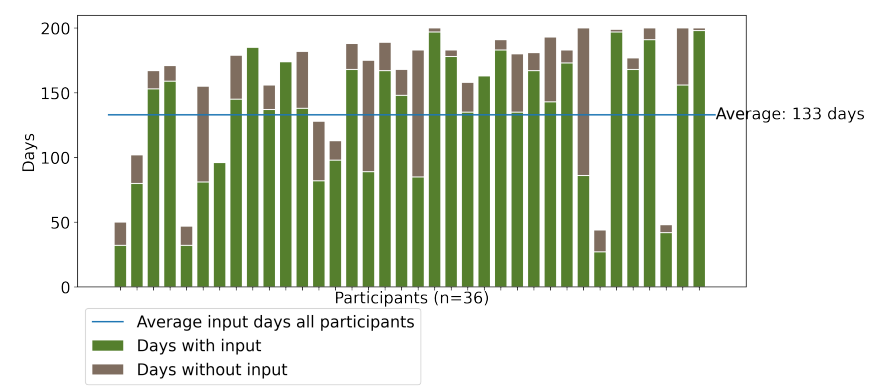

(a) Number of days with and without tablet input in trial per participant

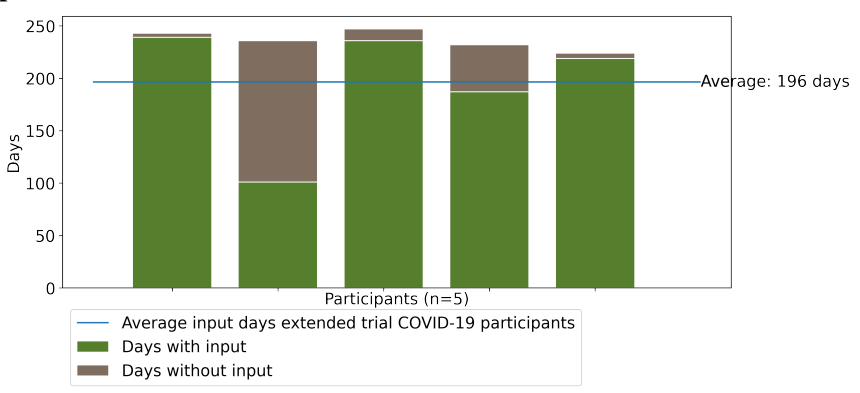

(b) Number of days with and without tablet input in trial per participant in COVID-19 extension

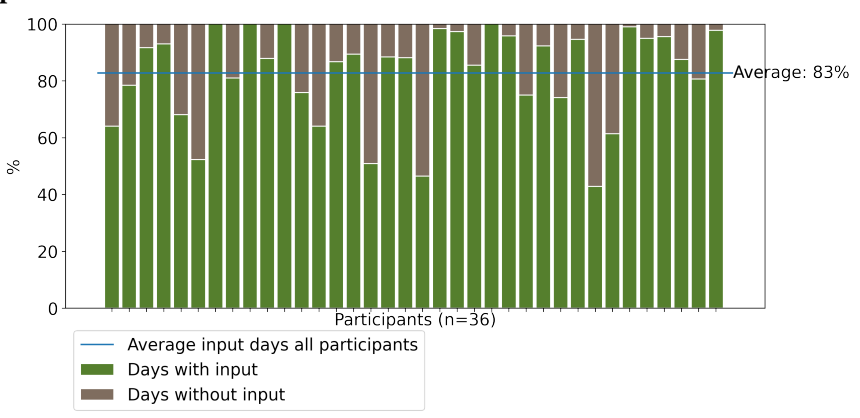

(c) Percentage (in)active days in trial per participant

Figure 2: Trial durations

the change between baseline and 6-months (coefficient $=0.090, \mathrm{p}$ value $=0.600$ ), and the mean intake at 6-month (coefficient $=0.183$, $\mathrm{p}$-value $=0.285)$ the Pearson coefficients are not significant.

\subsection{Experience diet}

After 6 months, the dietary evaluation questionnaire (see Appendix A.1) is used to assess the experience of users with the dietary advise. We compare the PT group with the no PT group to see if there are significant differences for these questions. The results are shown in Table 3. We do not find significant differences for any of the measures. However, for both the usefulness of the dietary advice and the ease to find products, we see that the sub study have a slightly better appreciation. Especially the ease to find products is one of the goals of the app.
Table 2: Results Student's t-tests for protein intake (expressed in $\mathrm{g} / \mathrm{kg}$ adjusted $\mathrm{BW} / \mathrm{d}$ )

\begin{tabular}{|l|l|l|l|}
\hline Measures & Means PT & $\begin{array}{l}\text { Means no } \\
\text { PT }\end{array}$ & P-values \\
\hline $\begin{array}{l}\text { Mean protein intake } \\
\text { at 3-months }\end{array}$ & $\begin{array}{l}1.237 \\
\mathrm{SD}=0.245 \\
(\mathrm{n}=34)\end{array}$ & $\begin{array}{l}1.311 \\
\mathrm{SD}=0.230 \\
(\mathrm{n}=38)\end{array}$ & 0.194 \\
\hline $\begin{array}{l}\text { Mean protein intake } \\
\text { at 6-months }\end{array}$ & $\begin{array}{l}1.242 \\
\mathrm{SD}=0.194 \\
(\mathrm{n}=36)\end{array}$ & $\begin{array}{l}1.341 \\
\mathrm{SD}=0.285 \\
(\mathrm{n}=38)\end{array}$ & 0.086 \\
\hline $\begin{array}{l}\text { Change protein: base- } \\
\text { line and 6-months }\end{array}$ & $\begin{array}{l}0.409 \\
\mathrm{SD}=0.255 \\
(\mathrm{n}=36)\end{array}$ & $\begin{array}{l}0.508 \\
\mathrm{SD}=0.299 \\
(\mathrm{n}=38)\end{array}$ & 0.132 \\
\hline $\begin{array}{l}\text { Change protein: } \\
\text { 3-months and } \\
\text { 6-months }\end{array}$ & $\begin{array}{l}0.014 \\
\mathrm{SD}=0.283 \\
(\mathrm{n}=34)\end{array}$ & $\begin{array}{l}0.053 \\
\mathrm{SD}=0.265 \\
(\mathrm{n}=37)\end{array}$ & 0.549 \\
\hline $\begin{array}{l}\text { Change protein: base- } \\
\text { line and 3-months }\end{array}$ & $\begin{array}{l}0.414 \\
\mathrm{SD}=0.237 \\
(\mathrm{n}=34)\end{array}$ & $\begin{array}{l}0.468 \\
\mathrm{SD}=0.248 \\
(\mathrm{n}=38)\end{array}$ & \\
\hline
\end{tabular}

Table 3: Results statistical tests for diet evaluation questionnaire (range 1-5)

\begin{tabular}{|l|l|l|l|}
\hline Measures & Means PT & $\begin{array}{l}\text { Means no } \\
\text { PT }\end{array}$ & P-values \\
\hline $\begin{array}{l}\text { Rating dietary advice } \\
\text { (range 1-10) }\end{array}$ & $\begin{array}{l}8.389 \\
\mathrm{SD}=1.029 \\
(\mathrm{n}=36)\end{array}$ & $\begin{array}{l}8.513 \\
\mathrm{SD}=1.037 \\
(\mathrm{n}=37)\end{array}$ & 0.608 \\
\hline $\begin{array}{l}\text { Usefulness dietary } \\
\text { advice }\end{array}$ & $\begin{array}{l}4.250 \\
\mathrm{SD}=0.649 \\
(\mathrm{n}=36)\end{array}$ & $\begin{array}{l}4.108 \\
\mathrm{SD}=0.699 \\
(\mathrm{n}=37)\end{array}$ & 0.475 \\
\hline $\begin{array}{l}\text { Extend to which di- } \\
\text { etary advice is fol- } \\
\text { lowed }\end{array}$ & $\begin{array}{l}4.278 \\
\mathrm{SD}=0.615 \\
(\mathrm{n}=36)\end{array}$ & $\begin{array}{l}4.378 \\
\mathrm{SD}=0.492 \\
(\mathrm{n}=37)\end{array}$ & 0.087 \\
\hline $\begin{array}{l}\text { Ease to stick to di- } \\
\text { etary advice }\end{array}$ & $\begin{array}{l}3.944 \\
\mathrm{SD}=0.860 \\
(\mathrm{n}=36)\end{array}$ & $\begin{array}{l}4.054 \\
\mathrm{SD}=0.705 \\
(\mathrm{n}=37)\end{array}$ & 0.143 \\
\hline $\begin{array}{l}\text { Intend to continue to } \\
\text { follow dietary advice }\end{array}$ & $\begin{array}{l}3.944 \\
\mathrm{SD}=0.674 \\
(\mathrm{n}=36)\end{array}$ & $\begin{array}{l}4.000 \\
\mathrm{SD}=0.707 \\
(\mathrm{n}=37)\end{array}$ & 0.093 \\
\hline $\begin{array}{l}\text { Ease to find products } \\
\text { with similar protein } \\
\text { amount }\end{array}$ & $\begin{array}{l}3.889 \\
\mathrm{SD}=0.854 \\
(\mathrm{n}=36)\end{array}$ & $\begin{array}{l}3.784 \\
\mathrm{SD}=0.712 \\
(\mathrm{n}=37)\end{array}$ & \\
\hline
\end{tabular}

\subsection{Experience persuasive technology}

3.4.1 Evaluation questionnaire persuasive technology. Figure 4a shows the scores of the experienced effectiveness of the tablet. This shows that most participants find the tablet helpful (Q1) and the functionalities sufficient (Q2). However, the participants are more divided and less positive about how the tablet met their expectations (Q3). Participants are on average slightly negative about continuing to use the tablet after the study finishes (Q4). One of the participants added to this that he/she is now familiar with the protein diet. Another participant added to the Q4 that it would be 


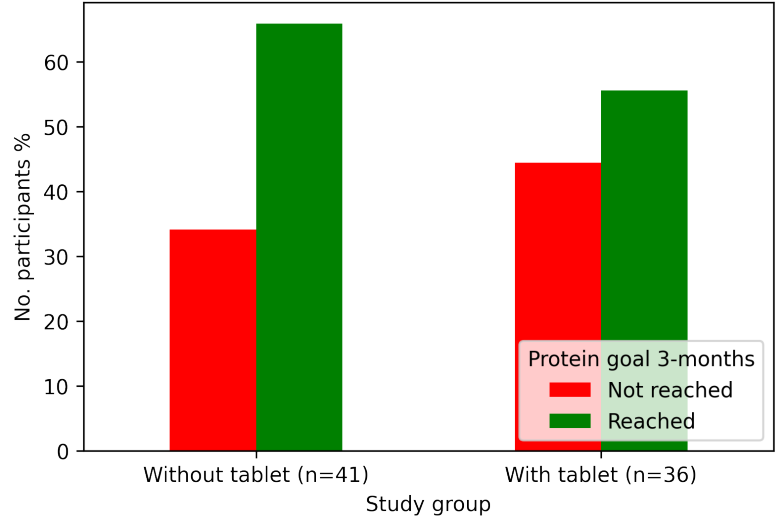

(a) Reaching protein goal at 3-months

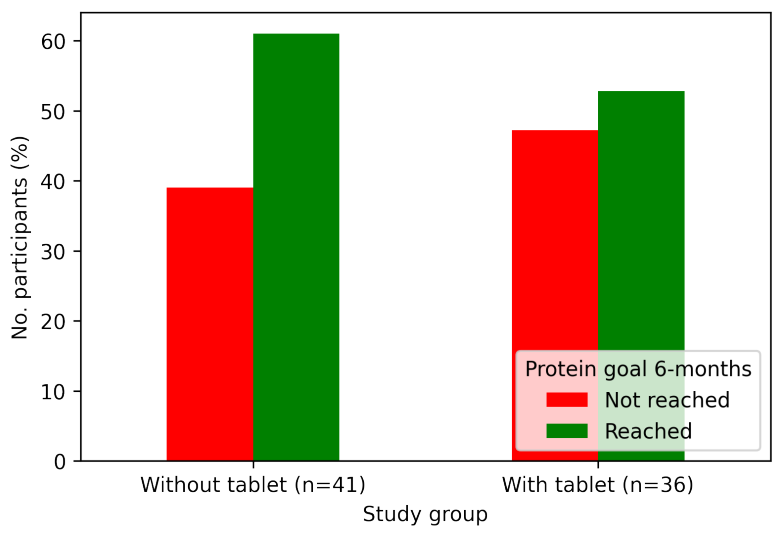

(b) Reaching protein goal at 6-months

Figure 3: Participants reaching 1.2 protein intake in $\mathrm{g} / \mathrm{kg}$ adjusted BW/d

nice to use the tablet from time to time, instead of every day. Overall, concerning the experience effectiveness (Q1-Q4), participants are slightly positive $($ mean $=4.573, \mathrm{SD}=1.945)$.

Figure $4 \mathrm{~b}$ shows the scores for the user-experience of the tablet. The only question that scores below neutral is the question about irregularities (Q6). During the trial different irregularities were found, some of which could not be solved during the trial. Overall, the user-friendliness is evaluated slightly positive, with an average score of 4.865 (SD = 1.990) for Q5-Q10.

Figure $4 \mathrm{c}$ shows the scores for the foodbox questions, on average, the questions Q11-Q13 are evaluated negatively (mean $=2.808, \mathrm{SD}$ $=1.788)$. Only the questions about ease to use (Q12) is evaluated a bit more positive.

There was some confusion among participants what we mean by notification messages. Moreover, for Q18 one participants answered both 4 and 5 , so we noted a score of 4.5 by exception. One participant added to the questions that he/she did not use the reminders, but filled in his/her consumption whenever it suited him/her. Most statements were evaluated neutral and with diverse scores, see Figure $4 \mathrm{~d}$. For the friendly tone (Q14), the score was a bit higher. In general, the notifications (Q14-Q21) are evaluated with an average score of $4.379(\mathrm{SD}=1.722)$.
Figure 4e shows that the scores about gamification (Q22-Q26) are very divided, and on average slightly above neutral (mean = $4.539, \mathrm{SD}=2.252$ ). For the mini-games participants are the most positive about the learning aspect of the games.

3.4.2 Interaction with the tablet. We also study how participants used the technology, which can give insights in which elements are used more often. Figure 5a shows how often, relative for each user, the three different input methods (fast input screen, meal composer, or via the foodbox) are used. As this is a relative graph, and we also take the extended trial due to COVID-19 into account. This shows that foodbox input is only used by a few participants. Moreover, we see that some participants use fast input for most inputs, while other participants use the meal composer most of the time. Only in a few cases, this is a bit more balanced. It needs to be noted that this graph does not correct for repeated inputs. Repeated inputs can be due to two reasons: a participant changes an input later or a participant repeats its input (for example to check it or to redo it).

In general, the meal composer is used $52 \%$ of the inputs, while fast input is used for $47 \%$ of the inputs, the foodbox is only used for $1 \%$ of the inputs. Participants can react in two ways to a notification that they receive: they can either confirm, meaning they start to enter their intake, or postpone the notification, which enables a reminder. Of the total of all the notifications send, $87 \%$ is ignored, $12 \%$ confirmed and $1 \%$ postponed.

To study how the gamification components were used, different types of interaction are studied. We did not clean the data to take into account the extension of the trial due to COVID-19. Only two participants from the gamification condition fell into this category. We did however check whether their data were different from the other participants.

On average, participants visited the profile page 41.526 times (SD $=41.611)$. Figure $5 \mathrm{~b}$ shows that there are quite some participants that only visit it less than 20 times. There are also two extremes of participants that visited it more than 100 times, which is not caused by the extension of the trial due to COVID-19. We can test whether there was a Pearson correlation between the days with input and the number of profile visits for participants. This correlation (0.032) is not significant ( $\mathrm{p}$-value $=0.179)$. Mini-games can be played when the threshold for a registration moment is met exactly. However, it is also possible to skip a game. Moreover, it was found that not all games that are started, are also finished. This can be due to a bug, that closes the screens when the mini-game was offered to the participant, but it can also be because the participant put the tablet aside during the game. Figure $5 \mathrm{c}$ shows that only 6 participants $(32 \%)$ of this condition played more than $50 \%$ of the mini-games that they were allowed to play. Some participants do not finish a single game.

\subsection{Gamification and protein knowledge}

In the dietary advice evaluation questionnaire, one question addressed whether the participants feel that they have a good understanding of the amount of protein in different types of products (see Appendix A.1). This question gives insight whether participants in the PT group gained more insight in protein products compared to the no PT group. In contrast to our expectations, the mean score of the PT group $(\mathrm{n}=36$, mean $=3.861, \mathrm{SD}=0.930)$ is lower compared 
to the no PT group $(\mathrm{n}=37$, mean $=4.108, \mathrm{SD}=0.737)$, this difference is significant ( $p$-value $=0.030)$. We also compared the normal condition $(\mathrm{n}=17$, mean $=3.941, \mathrm{SD}=0.827)$ with the gamification condition $(\mathrm{n}=19$, mean $=3.789, \mathrm{SD}=1.032)$, but these results turned out not significant $(\mathrm{p}$-value $=0.391)$.

Another way in which we can study the learning effect, is by looking at the scores in the first half of the games, and the scores in the last half of the games. For this, we combine all games per participant. With a Student's t-test, we test whether the differences between those means are significant. We include all participants from the gamification condition that played at least two games (14 participants). From these tests, it becomes clear that 5 participants made a significant change in their average points. For 4 of these participants this is an improvement, for one it is not, but this participant played a very low number of games compared to the other participants. It needs to be noted that the scores are not a complete representation of the knowledge of participants. We cannot see whether participants used their protein information booklet when playing the games, or whether this change is because they understood the games better.

We can also test whether there is a Pearson correlation between the number of games played and the average score of participants. The coefficient is 0.689 , with a significant $p$-value of 0.006 . Again, although the correlation is significant, it cannot be concluded based on this that the games contributed to more protein knowledge, as other explanations for this finding is also possible.

\section{DISCUSSION AND CONCLUSION}

This paper gives an overview of the most important results of the persuasive technology sub study of the PROMISS trial. We studied the adherence of participants, the change of the protein intake, the experience of the diet and the persuasive technology, and the impact of gamification on protein knowledge.

We find that participants of our study are $83 \%$ adherent to using the technology during their period of tablet use, on average 133 days. However, using the technology did not significantly change their protein intake compared to participants in the intervention groups without a tablet. We did not find an effect of the number of days that the tablet was used on the protein intake. During the study, it was noted that the tablet sometimes gives higher estimates of protein intake due to round differences with the dietitians. However, the results show that this does not have a significant negative effect on the protein intake of participants.

Participants with or without a tablet do not significantly evaluate the diet as a whole differently. On average, participants appreciate the tablet and the gamification elements, but the foodbox is negatively evaluated. When studying the interaction with the app, we find that participants often ignore the notification message, and instead interact with the app on their own initiative. Most participants either used the fast input or the meal composer most of the time, some participants used these input ways more balanced. For the mini-games we see a similar pattern: some participants skip all games, other participants play almost all games, only some participants play some games and skip some others.

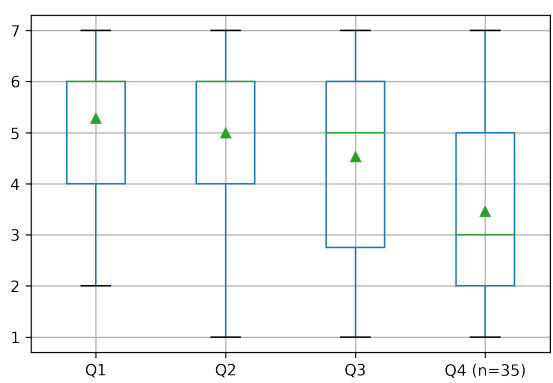

(a) Experienced effectiveness tablet $(n=36)$

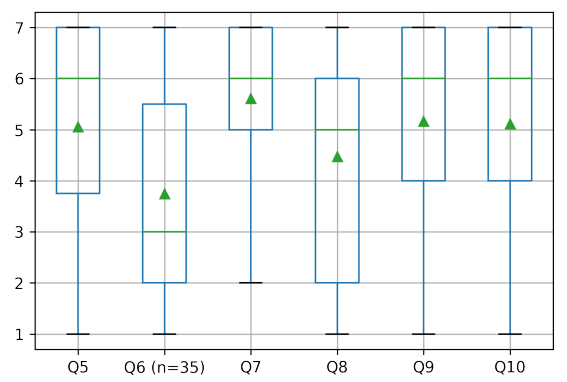

(b) User-friendliness tablet $(n=36)$

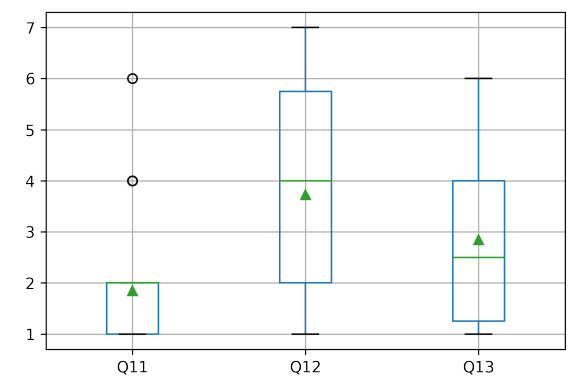

(c) Foodbox $(n=26)$

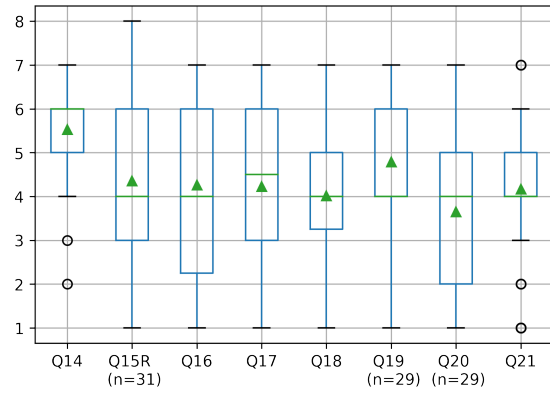

(d) Notification messages $(\mathbf{n}=30)$

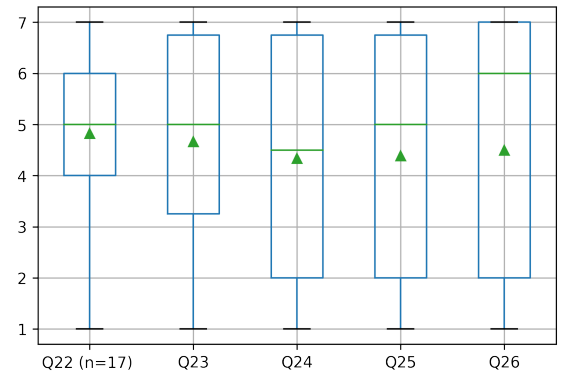

(e) Gamification $(\mathbf{n}=\mathbf{1 8})$

Figure 4: Boxplots PT evaluation questionnaire per topic, for all active participants - scale 1-7, $1=$ strongly disagree (negative evaluation), 7 = strongly agree (positive evaluation); question texts can be found in Appendix A.2 


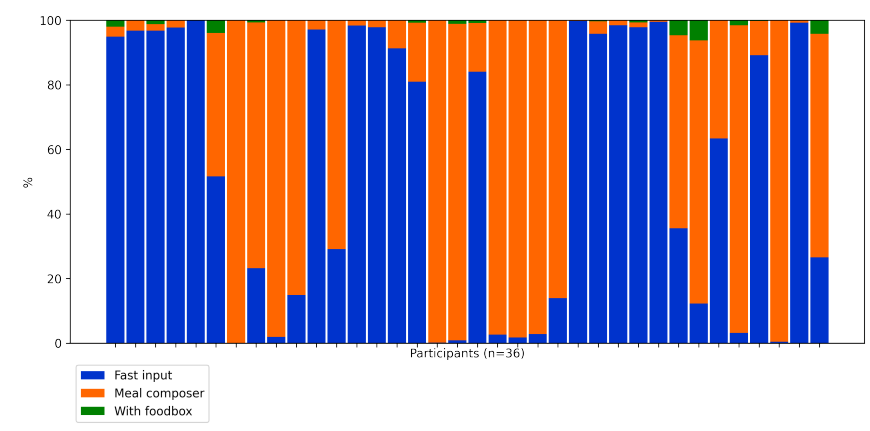

(a) Relative numbers of registrations on tablet with different input ways

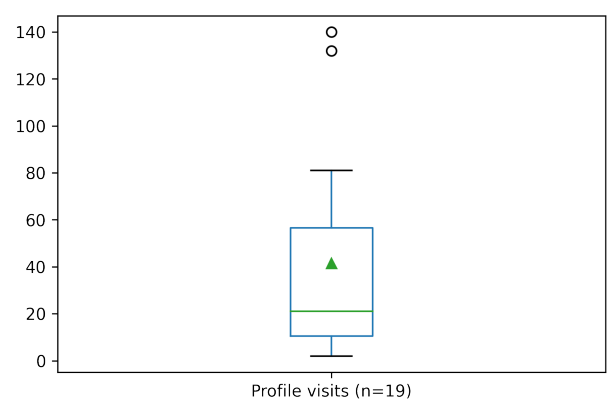

(b) Boxplot of profile page visits of gamification condition participants

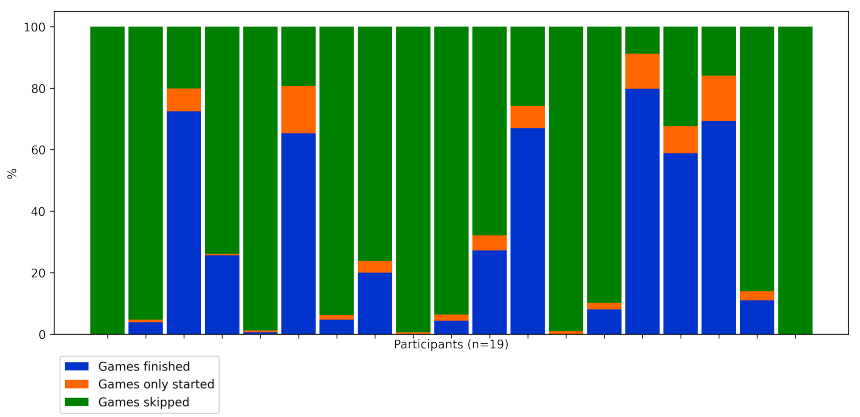

(c) Relative numbers of mini-games played and skipped per gamification condition participant

\section{Figure 5: Tablet interaction of participants}

Finally, we studied the learning effect of the mini-games. Based on a question about the understanding of protein this cannot be derived. From the scores of the games it seems that there is a learning effect for some participants. Moreover, the scores correlated with the number of games played. However, higher scores can also be due to other aspects, like using the information booklet. Altogether, we consider the app a feasible way to teach about protein intake.

There are some limitations to our study. The sample size of our sub study is 36, which is limited but sufficient for our analysis. For most research questions it is interesting to see whether there are differences between the two conditions (normal and gamification). This will be done in future work. However, when we study the different conditions, our sample size is small (17-19). Therefore, we cannot be sure whether the analysis would hold with a larger sample. Moreover, it might be that our participants have some different characteristic(s) which made them volunteer to participate in our study, which could have an effect on our results.

The adherence results could be influenced by some aspects. In Section 3.1 we already showed the small effect of excluding the drop-out participants. The results can also be influenced by the way we counted the duration of the tablet trial for each participant. We used the first and last day of use to calculate the trial duration. However, it could be that participants put the tablet aside for some time and start using it again right before an appointment. However, we did not find this in our data set. Some participants did not use the tablet for a longer period during their trial, sometimes due to issues or holidays and sometimes without a given reason. But they did start using it again for a considerable time before ending their use. For only one participant we found that there was around two weeks of inactivity, then five days of activity and then the participant stopped using the tablet.

During the study, it was sometimes necessary to fix some problems with the application. We also started with the inclusion for the gamification condition later in the study, when some first bugs were already fixed. it is possible that the evaluation and participation of participants is influenced by the number of bugs they encountered during their trial period. However, we do not find major differences in the average scores of the evaluation questionnaire.

This research does not look at the quality of the diet tracking data that participants enter in the app. We do not study whether the data from the tablet could be used by dietitians within the trial. For example, dietitians perform phone recalls during the trial to discuss the protein intake of participants. It would be interesting to study if the data from the tablet could replace such recalls. However, another research setup would be needed to address this.

Based on these results, we conclude that using a tablet with a diet tracking application, with persuasive communication, dedicated to the trial is a feasible way to engage participants. The target users, older adults, support the use of such persuasive technology, as shown by their evaluation of the system as well as the adherence to using it. In future research it is therefore interesting to study how such persuasive technology can be further integrated into a diet study, for example to support the work of dietitians.

\section{ACKNOWLEDGMENTS}

This work was supported by the European Union Horizon2020 PROMISS Project 'PRevention Of Malnutrition In Senior Subjects' (grant agreement no. 678732). We thank the PROMISS trial dietitians: Merel Vrijmoeth, Mariska Bout, and Marjon Veeke.

\section{REFERENCES}

[1] Michelle Clare Carter, Victoria Jane Burley, Camilla Nykjaer, and Janet Elizabeth Cade. 2013. Adherence to a smartphone application for weight loss compared to website and paper diary: pilot randomized controlled trial. fournal of medical Internet research 15, 4 (2013).

[2] Felicia Cordeiro, Daniel A Epstein, Edison Thomaz, Elizabeth Bales, Arvind K Jagannathan, Gregory D Abowd, and James Fogarty. 2015. Barriers and negative nudges: Exploring challenges in food journaling. In Proceedings of the 33rd Annual ACM Conference on Human Factors in Computing Systems. ACM, 1159-1162.

[3] Steven S Coughlin, Mary Whitehead, Joyce Q Sheats, Jeff Mastromonico, Dale Hardy, and Selina A Smith. 2015. Smartphone applications for promoting healthy 
diet and nutrition: a literature review. Facobs journal of food and nutrition 2, 3 (2015), 021.

[4] Daniel Johnson, Sebastian Deterding, Kerri-Ann Kuhn, Aleksandra Staneva, Stoyan Stoyanov, and Leanne Hides. 2016. Gamification for health and wellbeing A systematic review of the literature. Internet interventions 6 (2016), 89-106.

[5] Jonna Koivisto and Juho Hamari. 2014. Demographic differences in perceived benefits from gamification. Computers in Human Behavior 35 (2014), 179-188.

[6] Ilse Reinders, Hanneke A H Wijnhoven, Satu K Jyväkorpi, Merja H Suominen, Riikka Niskanen, Judith E Bosmans, Ingeborg A Brouwer, Kristien S Fluitman, Michel C A Klein, Lothar D Kuijper, Laura M van der Lubbe, Margreet R Olthof, Kaisu H Pitkälä, Rachel Vijlbrief, and Marjolein Visser. 2020 Effectiveness and cost-effectiveness of personalised dietary advice aiming at increasing protein intake on physical functioning in community-dwelling older adults with lower habitual protein intake. BMF Open 10, 11 (2020) arXiv:https://bmjopen.bmj.com/content/10/11/e040637.full.pdf

[7] Katie Seaborn and Deborah I Fels. 2015. Gamification in theory and action: A survey. International fournal of human-computer studies 74 (2015), 14-31.

[8] Emma K Stanmore, Alexandra Mavroeidi, Lex D de Jong, Dawn A Skelton, Chris J Sutton, Valerio Benedetto, Luke A Munford, Wytske Meekes, Vicky Bell, and Chris Todd. 2019. The effectiveness and cost-effectiveness of strength and balance Exergames to reduce falls risk for people aged 55 years and older in UK assisted living facilities: a multi-centre, cluster randomised controlled trial. BMC medicine 17, 1 (2019), 49

[9] L. M. van der Lubbe and M. C. A. Klein. 2019. Designing a System with Persuasive Communication to Improve Diet Compliance for Elderly Users. In Proceedings of the 13th EAI International Conference on Pervasive Computing Technologies for Healthcare (Trento, Italy) (PervasiveHealth'19). Association for Computing Machinery, New York, NY, USA, 234-241.

[10] L. M. van der Lubbe and M. C. A. Klein. 2020. Integrating Gamification into a System to Improve Diet Compliance for Elderly Users. In Proceedings of the 6th EAI International Conference on Smart Objects and Technologies for Social Good (Antwerp, Belgium) (GoodTechs '20). Association for Computing Machinery, New York, NY, USA, 150-155.

\section{A QUESTIONNAIRES}

\section{A.1 Dietary advice evaluation}

This questionnaire consists of seven questions about the following measures:

- Rating dietary advice (scale 1-10)

- Usefulness dietary advice

- Extend to which dietary advice was followed

- Ease to stick to dietary advice

- Intend to continue to follow dietary advice

- Understanding of protein in products

- Ease to find products with similar protein amount

If not indicated otherwise, the measure is evaluated on a 5-point Likert scale. To analyse the Likert scale questions, the Mann Whitney $\mathrm{U}$ test is used. For the rating we use a Student's t-test.

\section{A.2 Persuasive technology questionnaire}

Different topics are discussed in this questionnaire. The following topics and questions are asked (translated from Dutch):

- Experienced effectiveness tablet application

(1) The tablet helps/motivates me to stick to my dietary advice.

(2) The tablet has all the functionalities that I need.

(3) The tablet meets my expectation.

(4) If I would continue to follow my dietary advice, I would like to keep on using the tablet.

- User-friendliness tablet

(5) The tablet is easy to use.

(6) I did not encounter any irregularities when using the tablet.

(7) I quickly knew my way around with the tablet.
(8) I would recommend the tablet to someone else.

(9) The tablet was comprehensible.

(10) It was fun to use the tablet for following my dietary advice.

- Foodbox questions

(11) If I would stick to my dietary advice, I would like to continue to use the foodbox.

(12) The foodbox is easy to use.

(13) It was fun to use the foodbox when following my dietary advice.

- Notification messages

(14) The messages have a friendly tone.

(15) The messages are compelling.

(16) The messages are relevant for my personal situation.

(17) The messages are motivational.

(18) The messages are interesting to read.

(19) The messages are believable and trustworthy.

(20) The messages are about obstacles that I encounter.

(21) The messages suit my age and perceptions.

- Gamification

(22) I was motivated by my profile page.

(23) I was motivated by achieving an achievement.

(24) I found playing games motivating.

(25) I liked playing the games.

(26) I found the games informative.

All questions for this questionnaire could be rated on a 7-point Likert scale ( 1 =strongly disagree, $4=$ neutral, $7=$ strongly agree). Questions 15 is a negatively framed question, the scores are therefore reversed in the analyses. A Mann Whitney U test is used to compare the mean scores of different groups, if applicable. 